\title{
Incidence of strabismus, strabismus surgeries, and other vision conditions in Prader-Willi syndrome: data from the Global Prader-Willi Syndrome Registry
}

\author{
Jessica E. Bohonowych ${ }^{1}$, Caroline J. Vrana-Diaz ${ }^{1}$, Jennifer L. Miller², Shawn E. McCandless ${ }^{3}$ and Theresa V. Strong ${ }^{1 *}$
}

\begin{abstract}
Background: There is a relative lack of information on the incidence and treatment of vision problems in PraderWilli syndrome (PWS). Using data from the Global PWS Registry, we performed a cross-sectional study of vision problems in PWS.

Methods: Data, reported by caregivers who completed the Vision Survey in the Global PWS Registry between May of 2015 and March of 2020, were analyzed using descriptive statistics.

Results: There were 908 participants in this survey, with a mean age of 14.5 years (range 0-62 years). The prevalence of strabismus in this population was $40 \%$, with no statistically significant difference in prevalence by genetic subtype. Ninety-one percent of participants with strabismus were diagnosed before 5 years of age. Of those with strabismus, $42 \%$ went on to have strabismus surgery, with $86 \%$ of those having their first strabismus surgery before 5 years of age and $10.1 \%$ having more than one strabismus surgery. Additional vision issues reported included myopia (41\%), hyperopia (25\%), astigmatism (25\%), and amblyopia (16\%).

Conclusions: The prevalence of strabismus, amblyopia, and hyperopia are considerably higher in the PWS population represented in the Global PWS Registry as compared to the general population. People with PWS should be screened early and regularly for vision problems.
\end{abstract}

Keywords: Prader-Willi syndrome, Strabismus, Vision, Registry

\section{Background}

Prader-Willi syndrome (PWS) is a rare genetic disorder with an estimated birth prevalence of 1 in 15,000 individuals, affecting males and females equally, as well as all races and ethnicities [1-3]. PWS is caused by the loss of expression of paternally-expressed genes on chromosome 15q11.2-q13, with $\sim 60 \%$ of cases due to a deletion of the paternal allele in this region (del), $35 \%$ of cases resulting from maternal uniparental disomy 15 (UPD),

\footnotetext{
* Correspondence: theresa.strong@fpwr.org

${ }^{1}$ Foundation for Prader-Willi Research, Walnut, CA, USA

Full list of author information is available at the end of the article
}

and the remainder of cases caused by imprinting center defects $(3-5 \%)$ or chromosomal translocations $(<1 \%)$ [4].

Infants with PWS exhibit hypotonia, decreased movement and feeding difficulties [1-3]. Additional clinical manifestations develop in childhood, including short stature, distinct craniofacial characteristics, hypogonadotropic hypogonadism, scoliosis, cognitive delays, behavioral challenges, hyperphagia, and obesity [1-4]. To date, the only approved treatment for PWS is growth hormone $(\mathrm{GH})$ therapy, which is approved for use in children with PWS and has been shown to improve height

(c) The Author(s). 2021 Open Access This article is licensed under a Creative Commons Attribution 4.0 International License, which permits use, sharing, adaptation, distribution and reproduction in any medium or format, as long as you give appropriate credit to the original author(s) and the source, provide a link to the Creative Commons licence, and indicate if changes were made. The images or other third party material in this article are included in the article's Creative Commons licence, unless indicated otherwise in a credit line to the material. If material is not included in the article's Creative Commons licence and your intended use is not permitted by statutory regulation or exceeds the permitted use, you will need to obtain permission directly from the copyright holder. To view a copy of this licence, visit http://creativecommons.org/licenses/by/4.0/ The Creative Commons Public Domain Dedication waiver (http://creativecommons.org/publicdomain/zero/1.0/) applies to the data made available in this article, unless otherwise stated in a credit line to the data. 
velocity, body composition, motor development, and quality of life [5-10].

Among the craniofacial features of PWS, a variety of eye and visions issues have been reported, including strabismus. The reported prevalence of strabismus in PWS varies from 28 to $95 \%$ [11], but most studies to date have included relatively small numbers of participants. Additional vision deficits have also been documented in PWS with varying frequencies, including myopia, hyperopia, amblyopia, and astigmatism [11]. Considering the few reports on prevalence of vision issues in PWS, and lack of information on corrective vision surgeries, we used data from the Global PWS Registry [12] to perform a cross-sectional prevalence study on vision problems in PWS.

\section{Methods}

This is an observational retrospective study using data collected from the Global PWS Registry. All protocols and surveys were reviewed and approved by the New England Institutional Review Board (NEIRB). Informed consent was obtained from all subjects or, if subjects were under 18, from a parent and/or legal guardian. Surveys are typically completed by parents/caregivers of individuals with PWS, and in some instances, by the individual with PWS themselves [12]. The study population included participants who completed the vision survey between May-2015 to March-2020. Not all questions were completed by all respondents, thus the number of responses per question varies. Descriptive analyses were performed (proportions, means and standard deviations). Cochran-Mantel Haenzel tests and Chi-Squared tests were performed to compare eye condition prevalence by genetic subtype and growth hormone use. Analyses were performed in Microsoft Excel and SAS 9.4 (SAS Institute, Inc., Cary, NC). $P$-values of $<0.05$ were considered statistically significant.

\section{Results}

\section{Participant demographics}

The demographic information for the study cohort is provided in Table 1. This includes participants in the Global PWS Registry who completed the Vision survey over a several year period (May-2015 to March-2020). Ninety-three percent of participants have seen an ophthalmologist at some point in their life.a

\section{Strabismus}

The prevalence of strabismus in this study cohort was $40 \%$ (Fig. 1). There was no statistically significant difference in strabismus prevalence between the major genetic subtypes (Deletion: $41.9 \%$, UPD: $43.6 \%, p=0.66$ ), nor by GH use (Never on GH: $41.2 \%$, GH initiated before 2 years of age: $47.4 \%, \mathrm{GH}$ initiated after 2 years of age:
Table 1 Demographic Information of Participants with PWS who completed the Global PWS Registry Vision Survey

\begin{tabular}{ll}
\hline Characteristics & $\begin{array}{l}\text { Study Participants } \\
(\boldsymbol{n}=\mathbf{9 0 8}) \mathbf{n}(\mathbf{\%})\end{array}$ \\
\hline Sex & \\
Female & $462(50.9)$ \\
Male & $446(49.1)$ \\
Missing & $3(0.3)$ \\
Mean age at survey completion (years), \pm SD & $14.5 \pm 11.5$ \\
Age range (years) & $0-62$ \\
Genetic Subtype & \\
Deletion & $422(49.3)$ \\
Uniparental Disomy (UPD) & $296(34.6)$ \\
Imprinting Defect (ID) & $25(2.9)$ \\
Translocation & $9(1.1)$ \\
Other & $15(1.8)$ \\
Don't Know & $89(10.4)$ \\
Missing & $52(5.7)$ \\
Country of Residence & \\
United States & $744(81.9)$ \\
Canada & $77(8.5)$ \\
Australia/New Zealand & $40(4.4)$ \\
Other (24 additional countries) & $46(5.1)$ \\
Missing & $1(0.1)$ \\
\hline PWS Prade-Win Syndrome
\end{tabular}

PWS Prader-Willi Syndrome

$40.3 \%, p=0.24)$. The age at strabismus diagnosis among Registry participants is shown in Fig. 2a. The majority of participants $(91 \%)$ were diagnosed before the age of 5 . Among the participants who were diagnosed with strabismus, $42 \%$ went on to have strabismus surgery (Fig. 2b). The age of participants at the time of their first strabismus surgery is shown in Fig. 3a. Eighty-six

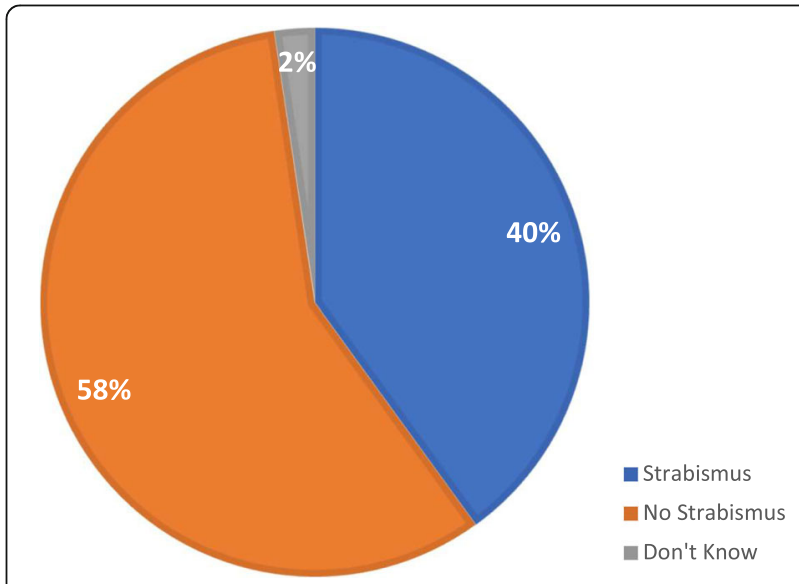

Fig. 1 Prevalence of Strabismus among Global PWS Registry Vision Survey. Respondents ( $N=887$ ) were asked if the participant (the individual with PWS) had "Strabismus (deviated eye, cross-eyed)" 


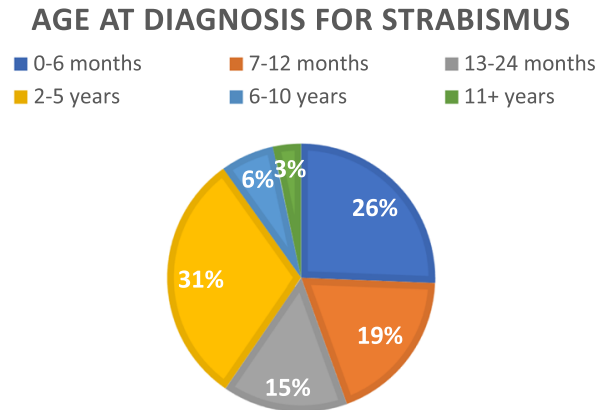

A

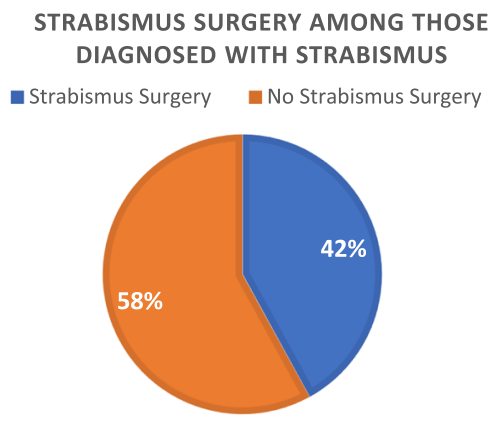

B

Fig. 2 Age at Strabismus Diagnosis and Prevalence of Strabismus Surgery. a. For those with strabismus, the age at which survey respondents were diagnosed with strabismus $(N=324)$. b: For those with strabismus, prevalence of those who went on to have strabismus surgery $(N=139)$

percent of participants had surgery before 5 years old. Among the population who had strabismus surgery, 125 participants had one surgery, 11 participants had two surgeries, and 3 participants had three strabismus surgeries (Fig. 3b).

\section{Other eye conditions}

Additional common vision issues in PWS were also reported in the Vision survey. Forty-one percent of participants had myopia (nearsightedness), $25 \%$ had hyperopia (farsightedness), $25 \%$ had astigmatism (imperfections in the eye curvature), and $16 \%$ had amblyopia (Fig. 4). The prevalence of hyperopia and amblyopia were not significantly different by the major genetic subtypes (Deletion: $26.9 \%$, UPD: $21.5 \%, p=0.11$, and Deletion: $17.4 \%$, UPD: $16.5 \%, p=0.77$, respectively). However, the prevalence of myopia and astigmatism were significantly different by major genetic subtype. For myopia, the prevalence was higher among those with deletion compared to UPD ( $44.3 \%$ vs. $35.6 \%, p=0.021$ ). For astigmatism, the prevalence was also higher among those with deletion compared to UPD ( $26.9 \%$ vs. $19.1 \%, p=0.018)$. There was no statistically significant difference in prevalence of other eye conditions by growth hormone use (hyperopia: Ever on GH: $23.7 \%$, Never on GH: $27.1 \%(p=0.51)$; myopia: Ever on GH: $39.2 \%$ Never on GH: $49.4 \%$ ( $p=$ 0.07); astigmatism: Ever on GH: $23.7 \%$, Never on GH: $29.4 \%(p=0.26)$; and amblyopia: Ever on $\mathrm{GH}: 15.8 \%$, Never on GH: $17.6 \%(p=0.66))$. A few other eye conditions were reported (e.g., nystagmus, blocked tear ducts, premature retinopathy), but none in more than $0.33 \%$ of the population.

\section{Discussion}

Although it is generally known that vision issues are common in individuals with PWS, there are few reports in the literature on prevalence, and an absence of information regarding corrective vision surgeries. This report on data from a cohort of participants within the Global PWS Registry highlights the breadth of vision issues in PWS, as well as the prevalence of corrective strabismus surgery.

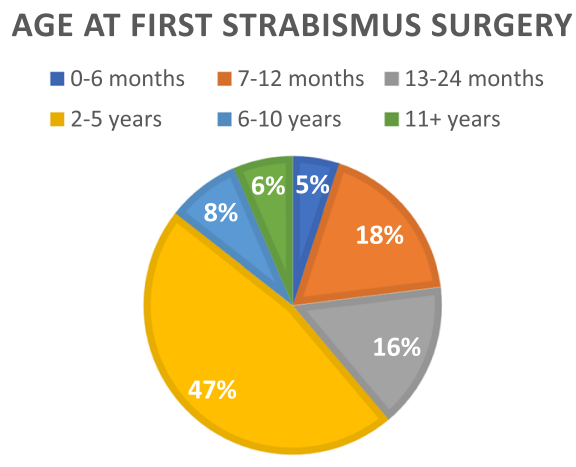

A

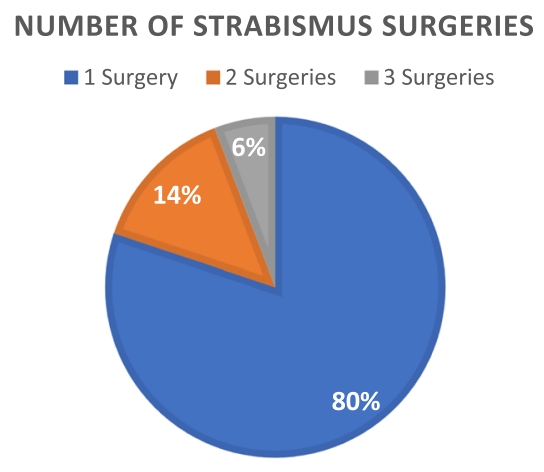

B

Fig. 3 Age at First Strabismus Surgery and Number of Strabismus Surgeries. a: For those who ever had strabismus surgery, age at their first strabismus surgery $(N=139)$, and $\mathbf{b}$ : Number of strabismus surgeries for those who ever had strabismus surgery and reported the number of surgeries $(N=139)$ 


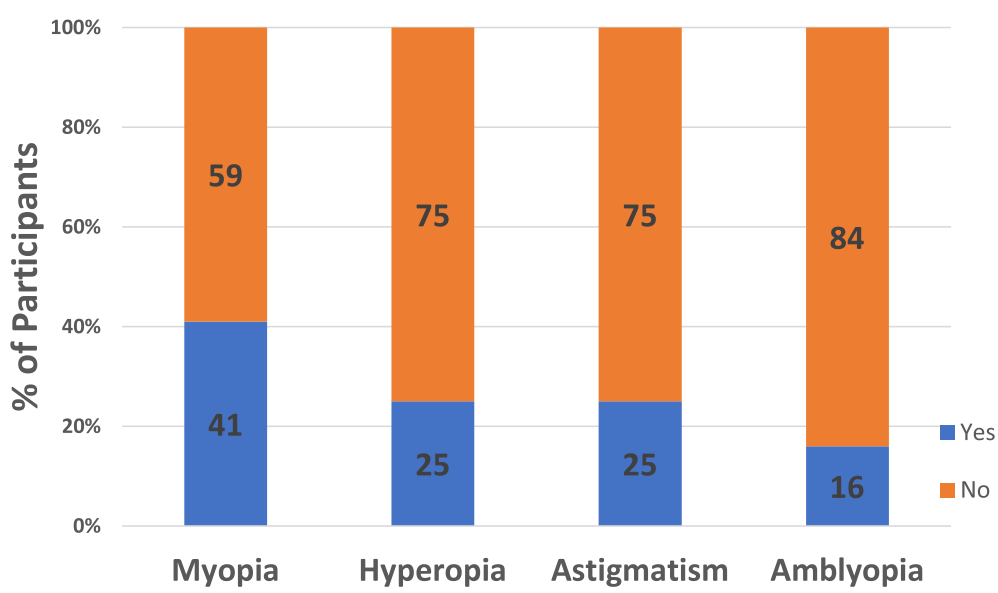

Fig. 4 Prevalence of other eye problems in PWS from Vision Survey. Answer options included "Near sightedness, difficulty seeing distant objects", reported here as myopia, "Far sightedness, difficulty seeing close objects", reported here as hyperopia, "Astigmatism, curvature of the lens", and "Amblyopia, lazy eye". Respondents ( $N=887)$ may have received more than one diagnosis of additional eye problems

Among participants within the Global PWS Registry who have completed the vision survey, the prevalence of strabismus $(40 \%)$ is much higher than that in the general pediatric population, which ranges between 2.1 and $3.6 \%$, depending on race and ethnicity [13-15], and also much higher than the prevalence of strabismus among all age groups in the IRIS registry, which contains over 30 million patients (2.75\%) [16]. Previous reports of strabismus among individuals with PWS range from 28 to $95 \%$ [11]. Most recently, a clinical study of the effect of growth hormone therapy on 355 PWS participants reported a strabismus prevalence of $42 \%$, which is line with the results reported here [17]. That study also showed a statistically higher prevalence of strabismus in individual with PWS by UPD versus those with the deletion subtype (53\% vs. $39 \%$ ) [17]. The current study of data from the Global PWS Registry, with almost 3 times the number of subjects, did not confirm this suggested difference in prevalence of strabismus by genetic subtype.

There are several hypotheses for the high rates of strabismus and other vision problems in PWS, including as a consequence of hypotonia, or alterations in typical facial morphology [11]. A 2019 study suggests a positive impact of GH therapy on strabismus, wherein the prevalence of strabismus was significantly lower in PWS individuals who had received GH therapy [18]. However, that study included a relatively small cohort of patients $(N=64)$, whereas a significant impact of GH therapy on strabismus was not reported in a larger PWS natural history study [17], nor in the Registry data represented here. Thus, additional data is needed to understand the impact of GH therapy on strabismus incidence and severity in PWS.

For Registry participants who report strabismus, the vast majority are diagnosed under the age of 5 (91\%).
The rate of surgery reported here among PWS individuals with strabismus (42\%) is consistent with a prior study where the percentage was $36 \%$ [19]. Both of these rates are much higher than in the general population where only $5 \%$ of people with a strabismus diagnosis received strabismus surgery [16]. In this report, for those participants who received a corrective strabismus surgery, the majority received their first surgery under the age of 5. This highlights that strabismus in PWS starts at an early age and examination by an ophthalmologist should be a pediatric priority in the PWS population. Importantly, $10.1 \%$ of Registry participants who underwent strabismus surgery went on to experience additional strabismus reoperation in the future, a similar rate to that reported in the IRIS registry (6.72\% reoperation within 1 year of strabismus surgery) [16].

Additional vision issues captured in the Vision survey of the Global PWS Registry include myopia, hyperopia, astigmatism, and amblyopia. Of these, the incidences of hyperopia and amblyopia were higher in this cohort than reported in the general population. Conversely, the prevalence of myopia was comparable to the general population, and astigmatism was lower. Specifically, the prevalence of hyperopia among Registry participants was higher $(25 \%)$ compared to the rates found in a metaanalysis of school-aged children $(8.4 \%$ among those 6 years old, $3 \%$ among ages $9-14$, and $1 \%$ among those 15 years old) [20], and higher compared to adults over 20 in an NHANES survey (3.6\%) [21]. The prevalence of myopia among Registry participants (overall: $41 \%$; Deletion: $44.3 \%$, UPD: $35.6 \%$ ) was relatively similar to both a large pediatric cohort in California (42\%) [22] and to adults over 20 in an NHANES survey (33.1\%) [21]. Interestingly, the prevalence of astigmatism (overall: $25 \%$; Deletion: 26.9\%, UPD: $19.1 \%$ ) among Registry 
participants was lower than the $41 \%$ previously reported in individuals with PWS [19] and lower than the prevalence among adults over 20 in a national NHANES survey $(36.2 \%)$ [21].

The prevalence of amblyopia among Registry participants $(16 \%)$ was higher than the amblyopia prevalence in the general pediatric population, which is reported to range between 1.5 and $2.6 \%$, depending on race and ethnicity $[13,14]$. This is an important issue for follow up because amblyopia is typically considered an avoidable complication if strabismus is diagnosed early and if effective treatment is provided. It raises questions about the utilization and efficacy of patching in this population, and whether PWS alone predisposes or increases the risk of amblyopia.

The high prevalence of a myriad of eye and vision problems in PWS may have far-reaching consequences. For a population that struggles with obesity due to a combination of hyperphagia (food-seeking behavior), hypotonia (poor muscle tone), and a lower resting metabolic rate, any additional impairments or challenges to physical activity can further contribute to weight gain. Impaired eye coordination or vision can negatively impact simple activities like walking, balance, and exercise. Moreover, impaired vision can impact learning, presenting additional challenges to a population that already faces intellectual disability, as well as cognitive and developmental delays.

The data from the Global PWS Registry may be limited by the self-reported nature of the surveys, however, the fact that the findings from this patient reported outcomes method correlate well with other, more traditional, sources, suggests that this is a generally robust mechanism for collecting this type of data on a large scale, complementing traditional natural history studies, which can be prohibitively expensive.

Finally, this report highlights that screening for and correcting vision deficits early in individuals with PWS is an important part of their clinical care.

\section{Conclusions}

This large-scale, representative survey of people with PWS showed a high prevalence of vision and eye problems, including strabismus, myopia, hyperopia, astigmatism, and amblyopia. While the incidence of myopia and astigmatism are similar or lower to what is reported in the general population, the incidence of strabismus, amblyopia, and hyperopia are all considerably higher. Moreover, for PWS individuals with strabismus, multiple corrective strabismus surgeries may be more common than in the general population. Children with PWS should be screened by an ophthalmologist for potential eye and vision issues. Early diagnoses can help families and practitioners develop an effective treatment plan.

\section{Acknowledgements}

We are grateful to the families who contribute data to the Global PWS Registry.

\section{Authors' contributions}

Conceptualization and development, J.E.B., C.J.V-D., and T.V.S.; methodology, J.E.B., J.M., S.E.M. and T.V.S.; analysis, J.E.B., C.J.V-D., and T.V.S.; data curation, J.E.B.; writing —original draft preparation, J.E.B., C.J.V-D., and T.V.S.; writing-review and editing, J.E.B., C.J.V-D., J.M., S.E.M. and T.V.S. All authors read and approved the final manuscript.

\section{Funding}

This research was funded by the Foundation for Prader-Willi Research.

\section{Availability of data and materials}

The datasets used and/or analyzed during the current study are available from the corresponding author on reasonable request, and approval from the Global PWS Registry Advisory Board.

\section{Declarations}

\section{Ethics approval and consent to participate}

This study was approved by the New England Institutional Review Board (IRB \#120190361) and informed consent was obtained from subjects or if subjects were under 18, from a parent and/or legal guardian. All methods were carried out in accordance with relevant guidelines and regulations.

Consent for publication

Not applicable.

\section{Competing interests}

J.E.B., C.J.V-D, and T.V.S. are employees of the Foundation for Prader-Willi Research. J.M and S.E.M declare that they have no competing interests.

\section{Author details}

${ }^{1}$ Foundation for Prader-Willi Research, Walnut, CA, USA. ${ }^{2}$ University of Florida, Gainesville, FL, USA. ${ }^{3}$ University of Colorado Anschutz Medical Campus, Aurora, CO, USA.

Received: 7 April 2021 Accepted: 9 July 2021

Published online: 12 August 2021

\section{References}

1. Driscoll DJ, Miller UL, Schwartz S, Cassidy S. Prader-Willi Syndrome. Adam M, Ardinger H, Pagon R, editors. Seattle (WA): University of Washington, Seattle. GeneReviews 2017.

2. Cassidy SB, Schwartz S, Miller JL, Driscoll DJ. Prader-Willi syndrome. Genet Med. 2012;14(1):10-26.

3. Angulo MA, Butler MG, Cataletto ME. Prader-Willi syndrome: A review of clinical, genetic, and endocrine findings. J Endocrinol Invest. 2015;38(12): 1249-63.

4. Butler MG, Miller JL, Forster JL. Prader-Willi Syndrome - Clinical Genetics, Diagnosis and Treatment Approaches: An Update. Curr Pediatr Rev. 2019; 15(4):207-44.

5. Bakker NE, Kuppens RJ, Siemensma EPC, Tummers-De LindWijngaarden Van Wijngaarden RFA, Festen DAM, Bindels-De Heus GCB, et al. Eight Years of Growth Hormone Treatment in Children With Prader-Willi Syndrome: Maintaining the Positive Effects. J Clin Endocrinol Metab. 2013;98(10):4013-22.

6. Dykens EM, Roof E, Hunt-Hawkins H. Cognitive and adaptive advantages of growth hormone treatment in children with Prader-Willi syndrome. J Child Psychol Psychiatry Allied Discip. 2017;58(1):64-74.

7. Siemensma EPC, Van Tummers-de LindWijngaarden RFA, Festen DAM, Troeman ZCE, Van Alfen-van Der Velden AAEM, Otten BJ, et al. Beneficial effects of growth hormone treatment on cognition in children with praderwilli syndrome: A randomized controlled trial and longitudinal study. J Clin Endocrinol Metab. 2012;97(7):2307-14.

8. Carrel AL, Myers SE, Whitman BY, Allen DB. Benefits of long-term GH therapy in Prader-Willi Syndrome: a 4-year study. J Clin Endocrinol Metab. 2002;87(4):1581-5. 
9. Lindgren AC, Lindberg A. Growth hormone treatment completely normalizes adult height and improves body composition in Prader-Willi syndrome: experience from KIGS (Pfizer international growth database). Horm Res. 2008:70(3):182-7.

10. Deal CL, Tony M, Hoÿbye C, Allen DB, Tauber M, Christiansen JS, et al. Growth hormone research society workshop summary: consensus guidelines for recombinant human growth hormone therapy in Prader-Willi syndrome. J Clin Endocrinol Metab. 2013;98(6):E1072-E1087.

11. Hurren BJ, Flack NAMS. Prader-Willi Syndrome: A spectrum of anatomical and clinical features. Clin Anat. 2016;29(5):590-605.

12. Bohonowych J, Miller J, McCandless S, Strong T. The Global Prader-Willi Syndrome Registry: Development, Launch, and Early Demographics. Genes (Basel). 2019;10(713):1-14.

13. The Multi-ethnic Pediatric Eye Disease Study Group. Prevalence of Amblyopia and Strabismus in African American and Hispanic Children Ages 6 to 72 Months: The Multi-ethnic Pediatric Eye Disease Study Multi-ethnic Pediatric Eye Disease Study Group * HHS Public Access. Ophthalmology. 2008;115(7):1229-36

14. McKean-Cowdin R, Cotter SA, Tarczy-Hornoch K, Wen G, Kim J, Borchert M, et al. Prevalence of amblyopia or strabismus in Asian and non-Hispanic white preschool children: Multi-ethnic pediatric eye disease study. Ophthalmology. 2013;120(10):2117-24.

15. Friedman DS, Repka MX, Katz J, Giordano L, Ibironke J, Hawse P, et al. Prevalence of Amblyopia and Strabismus in White and African American Children Aged 6 through 71 Months. The Baltimore Pediatric Eye Disease Study. Ophthalmology. 2009;1 16(11):2128

16. Repka M, Lum F, Burugapalli B. Strabismus, Strabismus Surgery, and Reoperation Rate in the United States: Analysis from the IRIS Registry. Ophthalmology. 2018;125(10):1646-53.

17. Mahmoud R, Leonenko A, Butler M, Flodman P, Gold J, Mille J, et al. Influence of molecular classes and growth hormone treatment on growth and dysmorphology in Prader-Willi syndrome: a multicenter study. Clin Genet. 2021;100(1):29-39.

18. Oldzej J, Manazir J, Gold JA, Mahmoud R, Osann K, Flodman P, et al. Molecular subtype and growth hormone effects on dysmorphology in Prader-Willi syndrome. Am J Med Genet Part A. 2020;182(1):169-75.

19. Hered RW, Rogers S, Zang YF, Biglan AW. Ophthalmologic features of Prader-Willi syndrome. J Pediatr Opthalmology Strabismus. 1988;25(3):145-50.

20. Castagno VD, Fassa AG, Carret MLV, Vilela MAP, Meucci RD. Hyperopia: A meta-analysis of prevalence and a review of associated factors among school-aged children. BMC Ophthalmol. 2014;14(1):1-19.

21. Vitale S, Ellwein L, Cotch MF, Ferris FL, Sperduto R. Prevalence of refractive error in the United States, 1999-2004. Arch Ophthalmol. 2008;126(8):1111-9.

22. Theophanous C, Modjtahedi BS, Batech M, Marlin DS, Luong TQ, Fong DS. Myopia prevalence and risk factors in children. Clin Ophthalmol. 2018;12: $1581-7$.

\section{Publisher's Note}

Springer Nature remains neutral with regard to jurisdictional claims in published maps and institutional affiliations.

\section{Ready to submit your research? Choose BMC and benefit from:}

- fast, convenient online submission

- thorough peer review by experienced researchers in your field

- rapid publication on acceptance

- support for research data, including large and complex data types

- gold Open Access which fosters wider collaboration and increased citations

- maximum visibility for your research: over $100 \mathrm{M}$ website views per year

At $\mathrm{BMC}$, research is always in progress.

Learn more biomedcentral.com/submissions 